\title{
Linguística, educação e política: para além da academia
}

\author{
Linguistics, education and politics: beyond academics \\ Lingüística, educación y política: Más allá del mundo académico \\ Mary Elizabeth Cerutti-Rizzatti ${ }^{1}$ \\ Hellen Melo Pereira (1) 1 \\ ${ }^{1}$ Universidade Federal de Santa Catarina, Florianópolis, SC, Brasil.
}

\section{RESUMO}

Este ensaio tem as relações entre Política, Linguística e Educação em Língua Portuguesa como tema, delimitando-se no questionamento acerca de em quê/como/de que modo os estudos linguísticos têm ou não contribuído para qualificar a abordagem escolar da linguagem em nível nacional. O conteúdo ocupa-se de problematizar questões como "O que os estudos linguísticos têm efetivamente feito em favor da qualificação do ensino e da aprendizagem de Língua Portuguesa nos estratos mais pobres da população brasileira? Em quê/como avanços nessa área do conhecimento reverberaram nacionalmente na educação em linguagem? E por que deveriam fazê-lo?" e inquietudes afins. Objetiva-se (i) argumentar contrariamente à denegação da abordagem epistêmica que se compreende ter tomado conta do campo da linguagem, e (ii) defender que o tensionamento dialético entre usos da língua e metacognição é condição para que a escola efetivamente contribua em um processo de formação dos estudantes que esteja comprometido com a emancipação humana, o que ganha especial sentido em um país com a forte conformação de fragilidades sociais como o Brasil.

Palavras-chave: Linguística. Educação Básica. Educação em Língua Portuguesa.

\section{ABSCTRACT}

This essay discusses the relationship among Politics, Linguistics and Education in Portuguese by delimiting itself in questioning how linguistic studies have or have not contributed to qualify the academic approach to language across Brazil. The content deals with questions such as: "What have linguistic studies actually done to improve the teaching and learning of the Portuguese Language across the poorest strata of the Brazilian population?; Have the advances in this area of knowledge really improved language education nationwide?; And why should they?". The objective is to focus on (i) the contradiction surrounding the denial of the epistemic approach based on the field of language, currently categorized according to speech and culture; an (ii) the opposition of the dialectical tension between 'uses of language' and 'metacognition', which enables schools to contribute effectively to a student training process that is fully committed to human emancipation, especially in a country where social fragilities are widely overlooked.

Keywords: Linguistics. Elementary Education Degree. Education in Portuguese Language.

\section{RESUMEN}

Este ensayo contiene las relaciones entre Política, Lingüística y Educación en la Lengua Portuguesa como tema, delimitándose sobre la cuestión acerca de en qué/cómo/de qué modo los estudios lingüísticos han o no contribuido a mejorar la calidad del abordaje escolar del lenguaje a nivel nacional. El contenido se enfoca en problematizar cuestiones como "¿Qué han hecho efectivamente los estudios lingüísticos a favor de la mejoría en la calidad de la enseñanza y del aprendizaje de la Lengua Portuguesa en los estratos más pobres de la población brasileña? ¿En qué/cómo avances en esa área del conocimiento reverberaron nacionalmente en la educación en lenguaje? ¿Y por qué deberían hacerlo?” e inquietudes relacionadas a estas. El Objetivo es (i) argumentar contrariamente a la denegación del abordaje epistémico que se comprende haberse apoderado del campo del lenguaje, y (ii) defender que la tensión dialéctica entre usos de la lengua y metacognición y condición para que la escuela efectivamente contribuya en un proceso de formación de los estudiantes que esté comprometido con la emancipación humana, lo que gana especial sentido en un país con la fuerte conformación de fragilidades sociales como es Brasil.

Palabras clave: Lingüística. Educación Básica. Educación en Lengua Portuguesa. 


\section{Introdução}

Vivemos em um país marcado por uma formação escolar pública absolutamente em xeque, para o que concorrem diversos fatores já amplamente conhecidos e que, como tais, colocam menções a eles, em revistas como esta, sob o risco de truísmo, mero senso comum, já que é difícil supor que as universidades brasileiras desconheçam a gravidade do cenário em nível nacional. Tomamos, porém, esse quadro de já ditos como necessário pano de fundo para a presente discussão, que, aqui, concerne ao campo dos estudos linguísticos. E a pergunta que move este ensaio é: o que os estudos linguísticos têm efetivamente feito em favor da qualificação do ensino e da aprendizagem de Língua Portuguesa nos estratos mais pobres da população brasileira? Parecem-nos inequívocos os substantivos avanços na ciência linguística nos últimos setenta anos no Brasil, daí por que a inquietude se coloca: em quê/como tais avanços reverberaram na educação em linguagem em nível nacional? E por que, nas compreensões que colocamos aqui, eles têm de reverberar nela? A excelência desses mesmos avanços tem extrapolado as ambientações seletas em que eles se consubstanciam, tendo presente que tais ambientações contrastam, ao fundo, com um quadro de pobreza, corrupção e alienação de boa parte da população ao acesso a bens culturais que transcendam seu próprio quintal?

Essa discussão se ocupa, assim, de problematizar tais questões, de modo a atender ao objetivo que a norteia, aqui retomado: argumentar contrariamente à denegação da abordagem epistêmica que se compreende ter tomado conta do campo da linguagem, e (ii) defender que o tensionamento dialético entre os usos da língua e a metacognição é condição para que a escola efetivamente contribua em um processo de formação dos estudantes que esteja comprometido com a emancipação humana, o que ganha especial sentido em um país com a forte conformação de fragilidades sociais como o Brasil. Isso posto, a hipótese de que partimos é esta: o progressivo apagamento da dimensão metacognitiva na educação escolar em linguagem tem contribuído para o esvaziamento dos processos educativos nessa área, em prejuízo, sobretudo, das populações socioeconomicamente fragilizadas, porque não lhes faculta a autorregulação da conduta na prática social em que se historiam como tais. Em decorrência disso, defendemos a tese de que importa reaver-se a metacognição na abordagem escolarobviamente em distinção de um anacronismo gramaticista cuja negação há muito está consensuada -; há que se o fazer no tensionamento dialético com a prática social e na atenção aos achados da ciência Linguística, tomados, esses últimos, rigorosamente como instrumentais e não com fins cientificistas em si e por si mesmos. Já quanto ao método que sustenta esta discussão, a argumentação arvora-se de base dialética.

\section{Uma palavra inicial: sobre os estudos linguísticos}

A Linguística é uma ciência? Xavier e Cortez (2003) fizeram, há alguns anos, essa mesma pergunta a linguistas de reconhecimento nacional, e as respostas certamente não podem ser resumidas em consensos de quaisquer tipos, porque no escopo delas está a complexa questão da filiação epistemológica sob a qual se toma o conceito de ciência. De todo modo, quer se assumam os estudos linguísticos por vertentes especulativas que engendram os seus enfoques na positivação do objeto de estudo, quer se faça isso por vertentes que o concebam pelo desiderato da emancipação humana, ou mesmo do mais monetário produtivismo, ou ainda do desiderato da paralogia (com base em LYOTARD, 1979), os estudos linguísticos ocupam espaço importante na esfera acadêmica, empregam profissionais de toda ordem e são destinatários de recursos públicos das mais importantes agências de fomento em nível nacional. Nessa condição, o campo precisa ser/é gerador de conhecimento. A questão que pontuamos aqui é o estatuto desse mesmo conhecimento.

Nessa linha de raciocínio, importa mencionar que, no âmbito das disciplinas híbridas, por exemplo, o advento da Sociolinguística e de áreas afins seguramente trouxe importante contribuição para que compreendêssemos o conceito de norma e todas as implicações que ele traz consigo, facultando-nos o refinamento de sopesar, desde Coserio (1979), custos sociais desse conceito, o que, em nível nacional, tornou-se uma fecunda área de produção acadêmica (a exemplo de FARACO, 2008; FARACO; ZILLES, 2017 e afins). Já a Psicolinguística, hoje na interface com a Neurociência, tem adensado o conhecimento sobre questões importantes como o processamento neural da leitura (DEHAENE, 2012) e discussões congêneres, também em crescente espraiamento no Brasil. No escopo do formalismo, estudos chomskyanos foram indiscutivelmente pródigos em explicar o inatismo da linguagem e, na descrição sintática das línguas, bem lecionaram a diversidade de gramáticas, o que persiste como campo fecundo, hoje em embrionárias interfaces com estudos neurais e afins darwinistas (PINKER, 2002; CHOMSKY, 2018). Seguramente esses são apenas alguns exemplos amplamente conhecidos de como a ciência Linguística produziu relevantes conhecimentos nos últimos setenta anos sobre a língua e sobre as línguas.

Em se tratando do campo aplicado - descurando, aqui, das já decantadas discussões sobre distinções 
entre Aplicação da Linguística ${ }^{1}$ e Linguística Aplicada (DAVIES; ELDER, 2004) -, o advento de estudos culturais, pós-coloniais e pós-estruturalistas tirou o foco da atividade humana vital como centro das discussões e o realocou quer na cultura, quer no texto/discurso ou na concomitância de ambos. Essa mudança de ênfase projetou uma sociedade atomicamente constituída em detrimento de uma sociedade marcada pela divisão de classes, e impôs intersecção de outras categorias - a exemplo de gênero e etnia - à categoria de classe social, problematizando os conceitos de verdade e cânone nas chamadas virada culturalista e virada linguístical discursiva. Nomes importantes como Michel Foucault, Jacques Derrida, Boaventura de Souza Santos, dentre outros, tornaram-se recorrentes referências no campo da Linguística Aplicada e das Análises do Discurso ${ }^{2}$. E, no âmbito destas últimas, tomou-se Mikhail Bakhtin, para a proposição da chamada Análise Dialógica do Discurso. Sob a égide desses movimentos, questões de fôlego como discussões sobre identidade, línguas minoritárias, gêneros, centralizações étnicas, teorias queer e temas congêneres ganharam espaço de relevância nos estudos linguísticos.

Assim considerando, o que move este ensaio é a compreensão de que a linguagem/as línguas é/são estreita implicação da humanidade do homem ${ }^{3}$, intricadas aí natureza e cultura. Impossível a condição do humano sem ela/elas, o que também é amplamente sabido. Então, se os estudos linguísticos têm a linguagem/as línguas como o seu objeto de estudo - considerada aqui a sublinha da Linguística Aplicada em tomar esse objeto necessariamente no imbricamento com os problemas sociais (MOITA LOPES, 2006) - em quê/como esses estudos linguísticos contribuem para a formação humana como tal? Adicionalmente a isso, compreendemos que, a despeito de alguns dentre os formalistas insistirem na aproximação da Linguística com as ciências exatas - sobretudo ao longo da segunda metade do século passado - ou com as ciências médicas - no affaire contemporâneo com a Neurociência - (conforme GERALDI, 2010), trata-se de um campo cuja gênese e cuja lógica são inextrincavelmente afetas às humanidades. E, sendo assim, importa que os estudos linguísticos se ocupem da humanidade do homem, o que, em países como o Brasil, exige que se considere politicamente o campo da Educação Pública.

\footnotetext{
Importa a lembrança, talvez desnecessária, de que sob a Aplicação da Linguística podem ser tomadas muitas das disciplinas híbridas, como a Psicolinguística Aplicada.

2 Foge ao propósito deste artigo a problematização de os "analistas do discurso" serem ou não "linguistas aplicados"; quer nos parecer, porém, que analistas do discurso tendem a atuar na Linguística Aplicada em programas de pós-graduação, por exemplo.

3 Prescindimos propositadamente da menção "homem/mulher" porque assumimos, aqui, todos os riscos de uma base ontogenética.
}

\section{Uma segunda palavra: sobre a educação em Língua Portuguesa}

Desde os Parâmetros Curriculares Nacionais (BRASIL-LP, 1998), as práticas sociais figuram oficialmente como o fio condutor da educação em Língua Portuguesa no cenário nacional. A obra Portos de Passagem, de João Wanderley Geraldi (1997), tornou-se quase que bíblica na busca por manter as práticas sociais como início, meio e fim da aula de Língua Portuguesa, e isso, a nosso juízo, constitui conquista inarredável. Nossa inquietação não está nesse quase consenso nacional de que as práticas sociais precisam ser o fio condutor dos percursos de ensino, pela óbvia razão de que não poderia ser diferente (apesar de a tradição escolarizante "insistir em insistir" no "gramatiquismo" por "décadas em décadas atrás"), já que a instituição escolar não teria razão de ser não fosse a formação crítica do sujeito para a vida em sociedade. $\mathrm{O}$ que nos inquieta é o aplanamento que inferimos tomarem as discussões de educação em Língua Portuguesa contemporaneamente e que tributamos a uma progressiva e preocupante denegação da dimensão necessariamente epistêmica da educação.

Estudos $^{4}$ de nosso Grupo de Pesquisa têm visibilizado uma questão desassossegadora que se materializa claramente em planos de ensino de Língua Portuguesa, especialmente no que tange ao item obrigatório desses planos, intitulado "conteúdos". E essa questão, a nosso ver, é apenas sintoma de uma tomada viral maior. $\mathrm{O}$ indiscutivelmente bem-vindo "apostolado" de Geraldi (1997) em favor das práticas sociais é renitente na argumentação de que um estudo nelas pautado inviabiliza estabelecimentos a apriori de conteúdos de ensino para Língua Portuguesa. Geraldi (2010a) volta a reiterar a "aula como acontecimento", com enfoque na aprendizagem e, nessa condição, impedida de orientar-se a partir de listagens de conteúdo. Nessa última obra, o autor faz uma lúcida crítica à prática de tornar gêneros do discurso objetos ontológicos, a compor "conteúdos" de ensino, o que remete à apropriação pedagógica "epidêmica" de tais gêneros, do que trata Faraco (2009).

Isso posto, porém, o que temos visto em tais planos de ensino são listas de conteúdos que desafiam quaisquer lógicas analíticas minimamente assentadas epistemologicamente, a exemplo de posposição, nessas listas, de itens como "figuras de linguagem; gêneros textuais; classes de palavras; leitura; interpretação; concordância; lendas; textos jornalísticos" cuja ordenação, assim, um após o outro, suscita que se trate de itens hierarquicamente correlatos, sem nenhuma distinção de

\footnotetext{
4 A exemplo de Irigoite (2011; 2015), Pereira (2015); Catoia Dias (2016); Tomazoni (2016); Cassol Daga (2016), dentre outros.
} 
ordem conceitual ou procedimental entre si e, talvez o mais grave, sem nenhum tipo de relação entre continente e conteúdo - tal como: lendas contêm figuras de linguagem, as quais, por sua vez, delineiam-se pelo agenciamento léxico-gramatical, o que implica classes de palavras; e lendas, na escola, são para leitura e interpretação. Logo, não se trata de itens que possam ser colocados lado a lado, como se, a cada aula, um deles fosse trabalhado em classe.

Dessas questões, todavia, nos ocupamos em CeruttiRizzatti e Pereira (2016) e Cerutti-Rizzatti e Chraim (2017). No presente ensaio, interessa-nos problematizar a seguinte questão, também reconhecida por Geraldi (2010a): professores tendem a "encontrar" conteúdos para colocar em seus planos de ensino, mesmo que a lógica do enfoque nas práticas sociais (BRASIL-LP, 1998) e no acontecimento (GERALDI, 2010a) desobrigue-os de fazê-lo. E, ao listar tais "conteúdos" na coluna a eles respectiva nos planos de ensino, confundem-se/misturamse/justapõem-se itens conceituais - como substantivos e afins - , itens procedimentais ${ }^{5}$ - como gêneros do discurso e afins - e itens de processamento da linguagem - como leitura e intepretação e afins. E, igualmente inquietante: parece-nos amplamente dado que o normativismo persiste, agora concorrendo com as práticas sociais e não a serviço delas (CATOIA DIAS, 2016; CASSOL DAGA, 2016).

$\mathrm{O}$ argumento que arriscamos apresentar aqui, porém, não é a favor do apagamento da coluna de "conteúdos" nos planos de ensino e da reiteração da desobrigação docente de listá-los. Nosso argumento é em favor do resgate da lógica dos "conteúdos" de Língua Portuguesa a partir de uma concepção de língua como interação social (VOLÓCHINOV, 2017). Defendemos, aqui, reaver-se a base epistêmica da educação em Língua Portuguesa, o que implica também a defesa da metacognição como questão relevante - logo, dos conteúdos como questão importante. Vale sublinhar que, por metacognição, para as finalidades deste ensaio, concebemos a abstração conceitual que faculta ao sujeito monitoramento da prática social, o que remete ao tensionamento, em espiral, de conceitos científicos e conceitos cotidianos, tal qual pontua Vygotski (1982). Compreendemos, assim, o domínio da abstração conceitual como a serviço da formação humana para autorregulação da conduta na prática social; logo, não se trata da metacognição em si e por si mesma, mas da abstração conceitual em favor da historiação da interação social.

\footnotetext{
5 Tomamos "procedimentais", aqui, como afetos ao "fazer linguagem na interação social"; corremos o risco do reducionismo do termo em nome da necessidade de marcar a distinção e à falta, por ora, de alternativa nominal mais apropriada. Seguramente gênero do discurso é conceito capital na formação docente, mas não conceito de tratamento didático, como tal, na esfera escolar, do que já se ocupou magistralmente Geraldi (2010a).
}

Entendemos que o estudante somente poderá autorregular a sua conduta nos usos da língua a partir do movimento que vai da prática social para a metacognição e retorna à prática social, do que deriva [deveria derivar] uma conduta irremediavelmente modificada, já autorregulada ou mais proximamente a isso (com base em VYGOTSKI, 2012). Estamos convictas de que a imersão nos diferentes usos da língua em si mesma não cria condições para que o sujeito possa ascender à autorregulação da conduta, porque a imersão faculta o feeling da adequação, mas não a avaliação conceitual abstrata acerca dela e, por implicação, a possibilidade de generalização a contextos correlatos.

Seguramente a imersão familiariza o sujeito com os diferentes usos da língua e contribui substancialmente para que se sinta confortável nesses mesmos usos, sem grandes titubeios quanto maior for a sua imersão. De todo modo, persiste a ancoragem pelo feeling: "soa", para o sujeito, que seja aquela a forma adequada à interação social em curso, mas esse mesmo sujeito não se apropriou conceitualmente dessa mesma forma para operar com ela consciente das especificidades de seu uso e das possibilidades de transgredi-lo ou não na relação social em que esse uso é agenciado. E entendemos que à escola compete historicamente a função de facultar essa autorregulação ao sujeito, evidentemente transcendido o absurdo da educação tradicional conteudista em si mesma, dissociada da prática social, já fartamente criticada nos "clássicos" da educação, a exemplo de Freire (2005) e Geraldi (1997). Pensamos que importa reaver o movimento defendido por Saviani (2008), que vai da prática social à metacognição e retorna à prática social, em movimentos dinâmico-causais de modificação a conduta, dada a possibilidade de operar conscientemente sobre essa mesma conduta (com base em VYGOTSKI, 2012).

Assim considerando, entendemos que, nos últimos quarenta anos (desde GERALDI, 1984) de discussões no campo do ensino e da aprendizagem de Língua Portuguesa, têm-se envidado todos os esforços possíveis para liberar o processo de ensino da metacognição. Compreendemos, porém, que tais esforços foram despendidos para liberação de uma metacognição sistêmica e objetivista (VOLÓCHINOV, 2017); e, como tal, reconhecidamente inócua. Nesse desiderato, porém, parece-nos que, equivocadamente, todo o tipo de metacognição passou a ser denegado. E, com isso, instaurou-se fortemente a virada linguística/discursiva e a virada culturalista em detrimento das bases epistêmicas do ensino e da aprendizagem de Língua Portuguesa (LP). Vemos nisso, hoje, substantivo problema para a educação em LP e, na próxima seção, ocupamo-nos de precisar por quê. 


\section{Uma terceira palavra: sobre quem recaem os custos dos percursos mencionados}

Há mais de três décadas vimos nos ocupando exclusivamente da educação em linguagem com enfoque na esfera escolar - sobretudo a pública - e, estando na esfera acadêmica, ocupamo-nos das relações desta com aquela esfera. Sentimo-nos, pois, autorizadas ${ }^{6}$ a afirmar que as escolas dos estratos mais pobres da população têm sido aquelas mais efetivamente prejudicadas pelo que entendemos serem gaseificações no ensino de Língua Portuguesa, e concebemos que a ciência Linguística tem contribuído substancialmente para essa gaseificação, à medida que, nos processos de formação e habilitação de licenciados em Letras, tende a deixar muito claro o que não deve ser feito, mas ocupar-se pouco do que deve ser feito e como deve ser feito (GIACOMINI, 2013).

Incomoda-nos especialmente a afirmação de que nós, linguistas 7 , temos sustentado que "não se ensina a língua materna". Importa que compreendamos que seguramente não se ensina uma língua que é materna ao sujeito, mas se ensina a ele sobre a sua própria língua em uma disciplina escolar, que, como tal, distingue-se do idioma, inclusive ao ser nomeada com iniciais maiúsculas, na condição de componente curricular: Língua Portuguesa. E o quê/por que o sujeito precisa aprender sobre a sua própria língua? Precisa dominar a adequação do uso dela nas interações sociais que não lhe são familiares e que precisam passar a ser para ampliação de repertório cultural. Se, por exemplo, é amplamente dado na ciência linguística que basta marcar o plural em um dos constituintes do sintagma, a exemplo de "Os livro verde", é também amplamente dado que, em determinadas interações sociais, espera-se que o plural seja marcado também nos demais constituintes, não por questões linguísticas - o plural consta já no início do sintagma, e todos os interactantes, ao ouvir a marcação no determinante, sabem que se trata de "mais de um" livro verde -, mas premidos por/integrados a acordos culturais historiados - e, sublinhe-se, sempre passíveis de ressignificação pelo importante e necessário tensionamento social -, o que inclui a modalidade escrita da língua.

Esse domínio da adequação - quando nós, falantes, podemos marcar o plural só no determinante e quando precisamos fazê-lo em todos os constituintes do sintagma - parece-nos questão já dada, pelo uso e não pela metacognição, aos estratos da população que gozam de escolaridade plena e para os quais o acesso aos bens

\footnotetext{
6 Nosso Grupo de Pesquisa "Cultura Escrita e Escolarização" levou a termo, de 2009 a 2018, oito Teses de Doutorado e vinte Dissertações de Mestrado sobre temas tais.

7 Autoqualificamo-nos como tais para fins de argumentação aqui, mas efetivamente nos autoconcebemos como "professoras".
}

culturais que transcendem o seu cotidiano imediato tende a ser amplamente assegurado por questões econômicas, que não gratuitamente são correlatas à alta escolaridade, com poucas exceções, as quais parecem se dar no campo das artes ou dos esportes ao gosto das mídias de massa as "celebridades" enriquecem sem necessariamente alta escolaridade, mas certamente esse é um grupo reduzido da população e de historicidade quase sempre marcada por alternâncias de es(ins)tabilidade econômica e, lamentavelmente, de (in)aceitação social correlata. Para as populações privilegiadas na conjugação "escolaridade" e "economia", autorregular a conduta linguística é questão facultada em seu dia a dia, nas interações familiares e de círculo social imediato, o que inclui frequência a espetáculos culturais, viagens de toda ordem, acesso a dispositivos eletrônicos de todo tipo e conteúdos a eles afetos. Trata-se, pois, de vivências cotidianas expandidas; para manter a metáfora: um quintal aberto ao mundo, ainda que problematizar adjetivação fecundas e inquietadoras para esse "mundo" não seja propósito deste ensaio.

Para nós, linguistas, professores universitários, plenamente inseridos em manifestações de toda ordem da cultura escrita, é tranquilo afirmarmos, por exemplo, que "não nos interessa saber como usar o acento indicador da crase" e prosaicas e, talvez irrelevantes, questões afins. Há, afinal, revisores para nossas publicações nos periódicos de prestígio nos quais as publicizamos, revisores a cujas intervenções nos submetemos sem grandes revoluções. Estando necessariamente imersos em manifestações de todo o tipo da cultura escrita, é exatamente do interior delas que podemos nos posicionar contrariamente a elas, criticando os "eurocentrismos", o "cânone", a "norma padrão" e temas afins. Tendoos dominado, conhecemos as suas fragilidades, as suas incongruências, as suas inadequações, o tanto de segregação cultural e de dominação política que há neles. $\mathrm{E}$, desse lugar, advogamos em favor de que outros não sejam submetidos a esse domínio: não se deve ensinar porque é incongruente, porque é inadequado, porque é segregador. Esses “outros", porém, só poderão ocupar os lugares que nós ocupamos hoje se, dentre algumas mais importantes exigências, dominarem também exatamente o que criticamos (mas dominamos). Para serem nossos pares, será requerido deles esse domínio. A questão talvez seja quantos pares queremos de fato a nosso lado, à medida que sua multiplicação incide diretamente sobre o status de "minoria" de que, alimentando-o ou detratando-o, inequivocamente gozamos.

A questão nodal que se coloca, porém, é que tais denegações vêm resultando em certezas docentes sobre o que não ensinar, mas nas muitas dúvidas sobre "o que ensinar" então. A resposta que temos dado no campo da ciência linguística é o "acontecimento" (GERALDI, 
2010a), mas o que vimos encontrando de fato, em muitas escolas, é a inquietude docente para assumir o acontecimento e lidar com ele. Dessa inquietude, temos visto decorrerem movimentos distintos, dos quais já tratamos em publicações de nosso Grupo de Pesquisa e aos quais já fizemos menção aqui em seção anterior: (i) a gaseificação da aula de Língua Portuguesa: cada dia um texto diferente (uma "folhinha" entregue aos alunos) com abordagens aplanadas que pouco contribuem para que o sujeito transcenda o seu próprio quintal (TOMAZONI, 2016); (ii) a objetificação dos gêneros do discurso, que levam professores a estudarem filigranas do jornalismo para distinguir com os alunos notícia de reportagem e questões controversas afins (CERUTTI-RIZZATTI; IRIGOITE, 2015); (iii) uma sucessão de itens nos programas escolares, de modo que hoje se ensina denotação e amanhã se ensina fábula e depois de amanhã se ensina substantivo, como entes absolutamente autônomos em si mesmos, para citar apenas um exemplo já mencionado antes neste ensaio (CERUTTI-RIZZATTI; CHRAIM, 2017); e (iv) a fidedignidade a livros didáticos de ampla homologação nacional que mantêm em um capítulo carta do leitor e, no seguinte, oração subordinada substantiva, para mencionar, de novo, apenas um exemplo (CASSOL DAGA, 2016), livros que servem ao enriquecimento de grandes corporações internacionais ${ }^{8}$, economicamente felizes em ofertar lenitivos à fragilizada esfera escolar brasileira por meio de vultosos editais governamentais 9 , do que já nos ocupamos em Cerutti-Rizzatti e Tomazoni (2016).

Enquanto boa parte das escolas públicas mantêm-se em alternâncias tais, muitas dentre as escolas privadas, em contrato de servilidade com as elites econômicas, atendem a familiares dos estudantes que pagam mensalidades para que seus filhos leiam a dita alta literatura e usem a língua sob os rigores da norma padrão (MOSSMANN, 2018). Temos convivido, em projetos de extensão nossos, com pós-graduados egressos de Programas de Linguística que, tornando-se professores em escolas tais, servem a matrizes curriculares com essas configurações, quer porque não tenham possibilidades de incidir sobre elas, quer porque terminem por se render a uma perversa lógica econômica na qual as elites alimentam a sua própria condição também por meio das escolas (com base em BOURDIEU;

\footnotetext{
8 A exemplo da bilionária incorporação da "Somos Educação" pela Kroton, o que inclui importantes editoras nacionais como Scipione, Saraiva e Ática, responsáveis por boa parte da circulação de livros didáticos no país. (Revista Veja - edição 2.580, ano 51, n. 18, 2 de maio de 2018)

9 Isso sob o beneplácito de muitos de nós, docentes, que enunciamos posicionamentos como: "É emocionante ver os olhos brilhantes dos alunos quando recebem livros didáticos novos" (Banco de dados do Grupo de Pesquisa Cultura Escrita e Escolarização). Prospectamos um tempo em que os olhos dos estudantes brilhem por receberem gratuitamente livros de poemas de Manoel de Barros, obras de Ondjaki ou compêndios de Filosofia.
}

PASSERON, 1982). E, assim sendo, agências de fomento nacionais, em um país pobre como o nosso, investem na formação de mestres e doutores, muitos dos quais se veem sob a premência de adaptação à lógica da escola privada porque a lógica da escola pública tende a lhes parecer fatalmente depauperante no que concerne à remuneração. Isso porque, diferentemente do que pensam muitos dentre nós, professores universitários, o mercado profissional não tem espaços vastos para docência, em Magistério Superior, na Linguística Formal ou na Teoria Literária. E os diplomas de Letras e de Linguística correm sério risco de obsolescência nas gavetas se muitos dentre seus portadores não se renderem à atuação na Educação Básica.

Como resultado, vemos o que Gramsci (1982) já denunciava: um tipo de escola para as elites e outro tipo de escola para os segmentos mais pobres da população, mas, aqui, interessam-nos essas diferenças no que respeita à Língua Portuguesa. A escola unitária em favor da qual advogava o filósofo italiano, para as finalidades deste ensaio, fica inviabilizada exatamente porque, enquanto, como linguistas, no desiderato de proteger os sujeitos contra o preconceito e a segregação, não lhes temos facultado usos da língua para além do seu próprio quintal. Sacralizamos o seu quintal, em ardorosas defesas de equanimidade, mas, ao fazê-lo, contribuímos substancialmente para que tais sujeitos se encapsulem nesse quintal sacralizado por nós. E, como escreve Harvey (2014) sob um escopo mais amplo, estetizar a pobreza pode contribuir para mantê-la como tal: conferir, por exemplo, ao funk condição de arte de prestígio vertente culturalista - ou trocar a designação "favela" por "comunidade" - vertente discursiva - pode concorrer para que secundarizemos a luta econômica em favor de que sujeitos vivam em melhores condições de habitação e que se apropriem de repertório cultural que lhes permita problematizar o hedonismo e a violência como matéria prevalente de produção de arte. Continuamos, pois, a compreender a matriz econômica como a gênese dos grandes problemas nacionais em países como o Brasil e que as intersecções que temos proposto ao conceito de classe social podem tergiversar a luta que efetivamente precisamos empreender, a luta pela equanimidade econômica.

Assim, enquanto vemos em escolas privadas os sujeitos retroalimentando as suas próprias representações de mundo, na amplitude que a posse econômica e a plena escolaridade conferem a seus quintais (com base em BOURDIEU; PASSERON, 1970), assistimos, nas escolas públicas, a meninos em fase final do Ensino Fundamental manifestarem amplas dificuldades, por exemplo, para controlar a corporeidade na concomitância ler a letra de uma música, cantar a música e dançar a partir da melodia (SOUZA, 2017), nos saraus que insistimos em manter em 
muitos espaços em que temos interagido, isso porque tais estudantes finalizam esse nível de ensino sem alfabetismo pleno e pouco familiarizados com representações culturais que extrapolem o raio geográfico de sua comunidade.

Esses estudantes estão na fila para o abandono da escola, para o subemprego, para o narcotráfico, para a maternidade/paternidade precoces, enquanto contemporâneos seus, no alto afunilado da pirâmide econômica, preparam-se para os cursos de Medicina, Direito, Arquitetura, Engenharia e congêneres em status econômico, preferencialmente nas universidades federais em que nós lecionamos, plenamente confortáveis com a norma culta (com base em FARACO, 2008), fartamente imersos na cultura escrita (com base em BRITTO, 2005) e, em pouco tempo, contratando em seus apartamentos de luxo com vistas panorâmicas aqueles que lhes foram contemporâneos na Educação Básica - mas no universo "exótico" da escola pública -, para que, com alfabetismo básico (ou menos que isso) sejam seus motoristas, suas arrumadeiras e serviçais afins ${ }^{10}$.

Nesse contexto, nós, professores universitários, a nosso turno, cruzamos todos os dias com sujeitos tais, que fazem a limpeza de nossos "laboratórios" e lavam nossos carros nos estacionamentos das universidades; invisíveis a nós, boa parte das vezes (TOMAZONI; PEDRALLI, 2014). Enquanto isso, ainda nós, linguistas de Lattes fartos, nos ocupamos com nossos pós-doutorados no Norte do mundo, incentivando nossos orientandos a nos repetirem e nos mantendo insones para contar os pontos que as agências de fomento esperam somar para aceder a nossas bolsas. E mais: persistimos falando da educação em linguagem no conforto de nosso ar condicionado e dizendo que "saber onde colocar o acento da crase" é questão que pouco importa.

\section{Uma palavra adicional: sobre por que temos cursos de Letras e Programas de pós-graduação em Linguística}

Entendemos que nenhum de nós, depois de Willian Labov, de Noam Chomsky, de Mikhail Bakhtin e de Michel Foucault, para citar apenas alguns dentre nossos "altares", defenderia uma educação em linguagem que não fosse crítica em relação a tudo quanto temos aprendido sobre a língua. Compreendemos, porém, que é chegada a hora de o ardor de nossas defesas mudar de acidez. Precisamos efetivamente formar sujeitos que estejam aptos para lidar com o movimento da prática social para a metacognição e, desta, de novo para aquela. Não é mais possível pensar que por feeling o sujeito vai autorregular a sua conduta;

\footnotetext{
10 Seguramente a equalização desses contextos não depende, vis-à-vis, da escola, mas, também seguramente, a escola é parte fundante no concurso para essa equalização.
}

não os mais pobres, porque o seu felling não lhes faculta um quintal de mundos para além de seu mundo imediato, e a escola é demasiado rarefeita para tal imersão efetiva.

Vygotski (1982) mostrou sobejamente a importância do tensionamento entre conceitos cotidianos - exauridos de experiência - e conceitos científicos - exauridos de abstração - para a autorregulação da conduta. Importa, assim, reaver a dimensão epistêmica do ensino de Língua Portuguesa, e importa que essa dimensão, distintamente do normativismo da década de 1970, seja agora derivada dos resultados dos estudos linguísticos, não na concepção academicista de que se possa fazer das aulas de Língua Portuguesa momentos de estudos dos fenômenos linguísticos (BORGES NETO, 2013 e formalistas afins); a lógica da disciplina científica não é a lógica da disciplina escolar. A língua, na universidade, é objeto de estudo e de pesquisa - logo, é a universidade o lócus para estudar os fenômenos linguísticos e gerar novos produtos culturais pela pesquisa -; já a língua, na escola, é objeto de ensino e aprendizagem, exatamente para garantir aos sujeitos que tais produtos dos estudos linguísticos contribuam para que os estudantes autorregulem a sua conduta nos usos da língua que transcendem o seu quintal. Insistimos: a escola é lugar de ensinar e de aprender sobre a língua, especialmente sobre os usos da língua que não são familiares aos sujeitos. Soares (1986), quatro décadas atrás, já propunha, a seu modo, um "bidialetalismo para a transformação". Os estudantes das escolas mais pobres precisam dominar a norma culta (com base em FARACO, 2008) da língua e precisam fazê-lo no movimento que vai da prática social - neste caso, na maioria das vezes, uma prática social desconhecida a eles - para a metacognição, com retorno à prática social, agora mais proximamente da autorregulação da conduta.

Sob essa perspectiva, o sujeito precisa compreender, por exemplo, que a sua língua materna tem diferentes formas de marcação de plural, dependendo de quais sejam as interações sociais firmadas por meio dela, e estar pronto para prescindir da tutela de outrem - o que inclui obras de referência como dicionários, gramáticas, descritivas ou normativas, sites de consulta aplanada e afins - quando lhe for requerido marcar plural de modos distintos do seu dia a dia. A escola é o lugar para que o sujeito compreenda isso, estando também apto a infringir intencionalmente o estabelecido, mas fazendo-o consciente de por quê/ como/em quê/de que modo o infringe, e isso requer metacognição na relação com a prática social.

Formar um licenciado em Letras apto a fazer esse movimento quando na docência é processo que exige outro tipo de base nos cursos de Letras Português. Dizendo de outro modo: trata-se de abrirmos mão de um cientificismo pretensioso segundo o qual, mantendo-nos 
distantemente delas, podemos saber o que deve ser feito nas escolas. É falacioso que nossas teorias nos bastem para o que propomos para a esfera escolar. Eis, aqui, a nosso juízo, o maior erro dentre os erros. Não é a matriz inata da linguagem, a inarredável variação das línguas, a força das formações discursivas ou o dialogismo inconteste dos enunciados, em si mesmos - para retomar apenas alguns de nossos "altares" a despeito de sua estupenda força teórica - que fundamentarão o cenário de um novo país na educação pública em linguagem. A tradição está ainda instalada nas escolas pública (GIACOMONI, 2013; CATOIA DIAS, 2016; CASSOL DAGA, 2016; PEREIRA, 2014; IRIGOITE, 2011, 2015); nunca saiu dela de fato. E os livros didáticos a endossam (CEREJA; MAGALHÃES, 2015, para citar apenas um exemplo), com "nosso endosso" acadêmico; afinal, nós compomos os circuitos de homologação desses livros no Programa Nacional do Livro Didático.

\section{Uma palavra final: sobre pungências}

Quando iremos efetivamente assumir a nossa brasilidade no que diz respeito à escola pública? Quando iremos compreender que os mais pobres são aqueles que mais precisam da nossa "majestosa" excelência acadêmica? Quando vamos entender que os Cursos de Letras Português não são palco das capas vermelhas de nossos currículos delineados para o beneplácito das agências de fomento? Quando nos renderemos à obviedade de que um país melhor, mais justo, mais crítico, mais equânime, menos corrupto depende, sim, da qualidade da escola pública - e que isso é bem mais do que cantilena de urna bienal?

Em que pese a força da sociologia crítica francesa do final do século passado, ou do poder argumentativo foucaultiano do "vigiar e punir", a escola é, sim, território de possibilidades, desde que desconfiemos de nossos "altares" e desvistamos a capa vermelha de nossa majestade acadêmica, nos ocupando minimamente das janelas - e não dos espelhos -, que nos mostram uma população analfabetizante, com o risco do neologismo, tão ao gosto das mazelas históricas que escorrem pelos nossos jornais diários. Não há humanismo fora da humanização, e a humanização distingue-se da hominização: podemos ser exemplares da raça humana sem nos comportarmos culturalmente como tais (com base em VYGOTSKI, 2003). A humanização exige educação, e a educação, para os pobres, exige uma escola pública de qualidade. Para que servem, em um país como o nosso, agências de fomento, bolsas de produtividade, revistas científicas de Qualis nobres se não for em nome da humanização? As janelas, e não os espelhos, são o desiderato do humano. $\mathrm{E}$ as universidades as têm mantido fechadas em favor do condicionamento do ar, condicionamento que vicia, porque nos adestra para um mundo paralelo ao mundo exterior e, em assim sendo, um mundo paralelo de ignorância do mundo exterior. Tristes tempos a produzir/ sendo produzidos por homens tristes.

\section{Referências}

BORGES NETO, José. Ensinar gramática na escola? ReVEL, [s. l.], edição especial n. 7, p. 68-83, 2013.

BOURDIEU, P.; PASSERON, J.-C. A reprodução: elementos para uma teoria do sistema de ensino. 2. ed. Rio de Janeiro: Francisco Alves, 1982 [1970].

BRASIL. SEF. Parâmetros curriculares nacionais: terceiro e quarto ciclos do ensino fundamental: língua portuguesa. Brasília: MEC/SEF, 1998.

BRITTO, Luiz Percival Leme. Letramento e alfabetização: implicações para a educação infantil. In: FARIA, Ana Lúcia Goulart de; MELLO, Suely Amaral. (org.). O mundo da escrita no universo da pequena infância. São Paulo: Autores Associados, 2005.

CATOIA DIAS, Sabatha. Entre ecos e travessias: um olhar para o ato de ler no processo de educação em linguagem na esfera escolar. Tese (Doutorado em Linguística) Universidade Federal de Santa Catarina, Programa de Pós-Graduação em Linguística, Florianópolis, 2016. https://doi.org/10.5007/2177-5230.2010v26n50p215

CEREJA, William Roberto; MAGALHÃES, Thereza Cochar. Português: linguagens, $9^{\circ}$ ano: língua portuguesa. 7 . ed. reform. São Paulo: Saraiva, 2015.

CERUTTI-RIZZATTI, Mary Elizabeth; PEREIRA, Hellen Melo. Por uma dimensão também conceitual da educação em linguagem: uma abordagem vigotskiana. Fórum Linguístico, Florianópolis, v. 13, n. 4, p.1587-1598, out./dez. 2016. https://doi.org/10.5007/1984-8412.2016v13n4p1587

CERUTTI-RIZZATTI, Mary Elizabeth. IRIGOITE, Josa Coelho da Silva. A aula de Português: sobre vivências (in)funcionais. A.L.F.A, São Paulo, v. 59, n. 2, p. 255-279, 2015. https://doi.org/10.1590/1981-5794-1504-2

CERUTTI-RIZZATTI, Mary Elizabeth; Chraim, Amanda Machado . Entrelugares e lugares na docência em Língua Portuguesa. Letra Magna (Online), [s. l.], v. 21, p.56-78, 2017.

CERUTTI-RIZZATTI, Mary Elizabeth; TOMAZONI, Eloara. Gêneros do discurso e educação em linguagem: i[in]quietudes. In: SOUZA, Sweder; SOBRAL, Adair (org.). Gêneros, entre o texto e o discurso. Campinas/SP: Mercado das Letras, 2016. p. 71-88. https://doi.org/10.5902/ 2176148525989

CHOMSKY, Noam. Sobre mentes e linguagem. ReVEL, [s. l.], v. 16, n. 31, p. 11-37, 2018. 
COSERIU, Eugenio. Teoria da linguagem e Linguística Geral: cinco estudos. Rio de Janeiro: Presença, 1979.

DAGA, Aline Cassol. O (ex)orbitar do ato de ler: um estudo sobre vivências de estudantes com a escrita em contexto de ambientação rural. Tese (Doutorado em Linguística) Universidade Federal de Santa Catarina, Programa de Pós-Graduação em Linguística, Florianópolis, 2016. https://doi.org/10.21840/siic/150549

DEHAENE, S. Os neurônios da leitura: como a ciência explica a nossa capacidade de ler. Tradução Leonor ScliarCabral. Porto Alegre: Penso, 2012.

DAVIES, A.; ELDER, C. (ed.). The handbook of applied linguistics. Oxford, UK: Blackwell, 2004.

FARACO, Carlos Alberto. Linguagem e diálogo: as ideias linguísticas do Círculo de Bakhtin. São Paulo: Parábola, 2009. https://doi.org/10.26512/les.v12i1.10544

FARACO, Carlos Alberto; ZILLES, A. M. S. Para conhecer norma linguística. São Paulo: Contexto, 2017. v. 1. https://doi. org/10.1590/2176-457337791

FARACO, Carlos Alberto. Norma culta brasileira: desatando alguns nós. São Paulo: Parábola Editorial, 2008.

FREIRE, Paulo. Pedagogia do Oprimido. Rio de Janeiro: Paz e Terra, 2005 [1967].

GERALDI, João Wanderley. Portos de passagem. 4 ed. São Paulo: Martins Fontes, 1997.

GERALDI, João Wanderley. A aula como acontecimento. São Carlos: Pedro \& João Editores, 2010a.

GERALDI, João Wanderley. Ancoragens bakhtinianas. São Carlos, SP: Pedro \& João Editores, 2010.

GERALDI, João Wanderley. (org.). O texto na sala de aula. 3. ed. São Paulo: Ática, 2001 [1984].

GIACOMIN, L. M. Os conhecimentos gramaticais na escola: 'regras' de um ensino sem regras. Dissertação (Mestrado em Linguística) - Programa de Pós-Graduação em Linguística, Universidade Federal de Santa Catarina, Florianópolis, 2013. https://doi.org/10.18226/610001/ mostraxvi.2016.45

GRAMSCI, Antonio. Os intelectuais e a organização da cultura. Trad. Carlos Nelson Coutinho. 3. ed. Rio de Janeiro: Civilização Brasileira, 1982 [194_].

IRIGOITE, Josa Coelho da Silva. Aula de Português como encontro entre a outra palavra e a palavra outra: um estudo sobre a ecologia da apropriação da escrita na esfera escolar. Tese (Doutorado em Linguística Aplicada) Universidade Federal de Santa Catarina, Programa de Pós-graduação em Linguística, Florianópolis, 2015. https://doi.org/10.5007/2177-5230.2010v26n50p215
IRIGOITE, Josa Coelho da Silva. Vivências escolares em aulas de Português que não acontecem: a (não) formação do aluno leitor e produtor de texto. Dissertação (Mestrado em Linguística Aplicada) - Universidade Federal de Santa Catarina, Florianópolis, 2011. https://doi.org/10.17771/ pucrio.pdpe. 23728

HARVEY, David. A condição pós-moderna. São Paulo: Loyola, 2014 [1989].

LYOTARD, J. F. A condição pós-moderna. Rio de Janeiro: José Olympio, 1979.

MOITA-LOPES, L. P. (org.). Por uma linguística aplicada indisciplinar. São Paulo: Parábola, 2006.

MOSSMANN, Suziane. Círculo de estudos de formação para a docência. Projeto de tese de doutorado. (Doutorado em Linguística) - Universidade Federal de Santa Catarina, Florianópolis, 2018. https://doi.org/10.4013/rechtd.2015. 72.01

PEREIRA, Hellen Melo. O lugar das práticas de letramento na esfera escolar: um estudo sobre o encontro aula de Língua Portuguesa. Dissertação (Mestrado em Linguística Aplicada) - Universidade Federal de Santa Catarina, Florianópolis, 2015. https://doi.org/10.1590/s0102-4450 2011000100004

PINKER, Steven. O instinto da linguagem: como a mente cria a linguagem. São Paulo: Martins Fontes, 2002.

SAVIANI, Dermeval. Escola e democracia. Campinas, SP: Autores Associados, 2008 [1983].

SOARES, Magda B. Linguagem e Escola: uma perspectiva social. São Paulo: Ática, 1986. https://doi.org/10.17851/24470554.4.4.74-75

SOUZA, Liliane Vanilde de. Vivências com o ato de ler na/ para além da esfera escolar. Dissertação (Mestrado em Linguística Aplicada) - Universidade Federal de Santa Catarina, Florianópolis, 2017. https://doi.org/10.24873/j. rpemd.2017.11.026

TOMAZONI, Eloara. $O$ ato de escrever em encontros na escola. Tese (Doutorado em Linguística Aplicada) Universidade Federal de Santa Catarina, Programa de Pós-graduação em Linguística, Florianópolis, 2016. https://doi.org/10.5007/2177-5230.2010v26n50p215

TOMAZONI, Eloara; PEDRALLI, Rosângela. Cultura escrita e grafocentrismo nos bastidores da universidade.

In: CERUTTI-RIZZATTI, Mary Elizabeth. (org.). Cultura escrita e escolarização: alfabetismo e leitura. Florianópolis: Insular, 2013. v. 2, p. 111-129.

VYGOTSKI, Lev Semenovich. Obras escogidas. Tomo I. Madrid: Machado Libros, 2013 [1920-30]

VYGOTSKI, Lev Semenovich. Obras escogidas: problemas de Psicología General. Tomo II. Madri: Visor, 1982 [1934]. 
VYGOTSKI, Lev Semenovich. Obras escogidas. Tomo III. Madrid: António Machado, 2012 [1931].

VOLOCHÍNOV, Valentin Nikolaevich. Marxismo e filosofia da linguagem. São Paulo: Editora 34, 2017.

XAVIER, Antonio Carlos; CORTEZ, Suzana. Conversas com linguistas. São Paulo: Parábola, 2003. https://doi.org/ $10.22456 / 2238-8915.29988$

Recebido em: 5/3/2018

Aprovado em: 12/9/2019.

Publicado em: 30/11/2019.

\section{Autoras:}

Mary Elizabeth Cerutti-Rizzatti

Doutora, professora adjunta da Universidade Federal de Santa Catarina, Florianópolis, SC, Brasil.

Orcid: https://orcid.org/0000-0002-6635-4245

E-mail: ma.rizzatti@gmail.com

Hellen Melo Pereira

Doutoranda, Universidade Federal de Santa Catarina, Florianópolis, SC, Brasil.

Orcid: https://orcid.org/0000-0001-7452-5705

E-mail: hellenmp@gmail.com

Endereço: Rua Eng. Agronômico Andrei Cristian Ferreira, s./n. - Trindade 88040-900, Florianópolis, SC, Brasil 